\title{
Medical Conditions
}

\author{
Attilio De Blasio
}

\subsection{Introduction}

An acute hypoxemic respiratory failure (AHRF) has high possibilities to develop acute respiratory distress syndrome (ARDS) and increased death risk. Although the prevalence of ARDS is about $10 \%$ of ICU admissions, this syndrome appeared to be underrecognised and undertreated and associated with a high mortality rate. Essential in recognition of the ARDS is to identify all patients with AHRF breathing with the aid of a ventilator [1]. AHRF which represents a common end-point to multiple pathological processes either local or systemic may have many medical conditions as aetiology. We can divide more or less the main determinants into two categories: pulmonary and extrapulmonary [2]. Table 11.1 listed the common causes of AHRF. Between pulmonary determinants, pneumonia and bacterial and virus infection diseases are the most frequent disease associated with AHRF [3]. The extrapulmonary sepsis, blood transfusions pancreatitis, and drug reaction are more frequent as extrapulmonary causes [4]. On the other side, chronic disease such as diabetes has been associated with a lower occurrence of ARDS [5]. Moreover, some demographic and environmental risk factors are related to the development of ARDS. These include older age and specific genetic variants [2, 6]. In this chapter, we review the medical diseases associated with AHRF and the related treatment options. The incidence of acute lung injury as a critical illness syndrome consisting of acute hypoxemic respiratory failure with bilateral pulmonary infiltrates lung increased with age from 16 per 100,000 person-years for those 15 through 19 years of age to 306 per 100,000 person-years for those 75 through 84 years of age. Mortality increased with age from $24 \%$ for patients 15 through 19 years of age to $60 \%$ for patients 85 years of age or older [7].

\footnotetext{
A. De Blasio $(\bowtie)$

Emergency Department, Maggiore Hospital, Parma, Italy
} 
Table 11.1 Medical diseases associated with acute hypoxaemic respiratory failure

\begin{tabular}{l|l}
\hline Infectious diseases & Non-infectious diseases \\
\hline $\begin{array}{l}\text { Virus (respiratory viruses, Herpesviridae, Influenza A } \\
\text { and B, coronavirus) }\end{array}$ & Aspiration of gastric contents \\
\hline $\begin{array}{l}\text { Bacteria (Streptococcus pneumoniae, Group B } \\
\text { streptococci, Group A streptococci, Haemophilus } \\
\text { influenzae, Mycoplasma pneumoniae, Chlamydia } \\
\text { pneumoniae, etc.) }\end{array}$ & Pulmonary contusion \\
\hline & Multiple transfusions \\
\hline & Pancreatitis \\
\hline & Toxic inhalation injury \\
\hline & Drug overdose \\
\hline
\end{tabular}

\subsection{Pulmonary and Extrapulmonary Infectious Diseases}

The rate of development of ARDS in severe sepsis is reported to be law. Furthermore, when ARDS developed, it developed rapidly and was associated with a high mortality rate. The initial serum lactate measurements and a validated clinical prediction score at the hospital admission can be used to risk-stratify patients with severe sepsis at high risk of ARDS development [8]. For the virus infection, ARDS may rarely be a complication of lung infection due to respiratory viruses, except for the most recent pandemic H1N1-2009 and H5N1 influenza A viruses that induced severe ARDS. Specific management includes antiviral treatment with oseltamivir (for influenza viruses) and the avoidance of corticosteroids which seem to be harmful. Ventilatory management of patients with virus-induced ARDS is the same as that for ARDS of other etiologies. The H1N1-2009 pandemic stimulated interest in ExtraCorporeal Membrane Oxygenation (ECMO) therapy [9]. The physiopathological role of infection such as pneumoniaa in Indirect lung injury, is well known. Various pathogens cause pneumonia, and occasionally pneumonia can progress to ARDS, multiple organ failure, and death. The pathogens causing pneumonia may be the cause of ARDS, and the immunopathogenesis of ARDS may be the same as that of pneumonia [10]. Although risk factors such as being an infant, being elderly, comorbidity with other diseases, and immunodeficient states are associated with the development of ARDS in various respiratory infections, including influenza virus infection, previously healthy patients can also develop ARDS. In addition, the majority of patients infected with respiratory pathogens such as influenza viruses and Mycoplasma pneumoniae (M. pneumoniae) may be asymptomatic or have mild symptoms.

\subsection{Non-infectious Extrapulmonary Causes}

Different non-infectious etiologic conditions, such as blunt chest contusion, multiple injuries, aspiration of gastric contents, inhalation burns, pancreatitis, and blood transfusions may cause ARDS. Although the pathogenesis in these conditions 
remains unknown, there should be etiologic substances that induce inflammation with immune cells and induce lung cell injury. The features of secondary ALI/ ARDS involve an initial exudative phase with diffuse alveolar damage, microvascular injury, type-I pneumocyte necrosis, and the influx of inflammatory cells, followed by a fibro-proliferative phase with lung repair and type-II pneumocyte hyperplasia and proliferation of fibroblasts [11].

\subsection{Medical Conditions and AHRF/ARDS Prognosis}

Many factors such as well-trained staff, age, chronic diseases burden, and nonpulmonary organ dysfunctions such as shock and hepatic failure influence the prognosis. Persistent hypoxemia has greater predictive value. ALI mortality was often reported to be 50-70\%, but fortunately, there has been an improvement [12]. The mortality has declined in recent years to $25-40 \%$, probably because of advances in mechanical ventilation and treatment of sepsis.

\subsection{Treatment of Medical Conditions Associated with Hypoxemic Respiratory Failure}

For acute hypoxemic ARF, there is the possibility of increasing the $\mathrm{FiO}_{2}$ level by several methods: high-flow nasal $\mathrm{O}_{2}$ therapy 'HFNOT' and non-rebreathing masks or the application of invasive/non-invasive MV and ECMO (extracorporeal membrane oxygenation) for a period to allow time for curative treatments [13]. A recent evidence showed that in patients with moderate to severe ARDS, a strategy with lung recruitment and titrated PEEP compared with low PEEP increased 28-day allcause mortality. Furthermore, these findings do not support the routine use of lung recruitment manoeuvre and PEEP titration in these patients [14]. The management of acute respiratory failure requires an integrative supports and an escalation therapeutic strategy [15]. Furthermore, currently, the use of NIV as an alternative to invasive ventilation in severely hypoxemic patients with ARDS is not generally recommended. NIV should be limited to highly selected haemodynamically stable patients who can be closely monitored in an intensive care setting by highly skilled staff with a readiness to promptly intubated if oxygenation fails to improve sufficiently within the first hour [16]. The new therapy with High-Flow Oxygen Therapy allowed the administration of warmed and humidified gas at very high-flow rates. This therapy improved patient oxygenation minimising the adverse effects [17]. The main benefit of this system is the patient's comfort.

\section{References}

1. Bellani G, Laffey JG, Pham T, et al. Epidemiology, patterns of care, and mortality for patients with acute respiratory distress syndrome in intensive care units in 50 countries. JAMA. 2016;315(8):788-800. https://doi.org/10.1001/jama.2016.0291. 
2. Rezoagli E, Fumagalli R, Bellani G. Definition and epidemiology of acute respiratory distress syndrome. Ann Transl Med. 2017;5(14):282.

3. Garcia CS, Pelosi P, Rocco PR. Pulmonary and extrapulmonary acute respiratory distress syndrome: are they different? Rev Bras Ter Intensiva. 2008;20(2):178-83. https://doi.org/10.1590/ S0103-507X2008000200011. [Cited 2019-01-24]. http://www.scielo.br/scielo.php?script=sci_ arttext\&pid=S0103507X2008000200011\&lng=en\&nrm=iso. ISSN 0103-507X.

4. Matthay MA, Zemans RL. The acute respiratory distress syndrome: pathogenesis and treatment. Annu Rev Pathol. 2011;6:147-63.

5. Yu S, Christiani DC, Thompson BT, Bajwa EK, Gong MN. Role of diabetes in the development of acute respiratory distress syndrome. Crit Care Med. 2013;41(12):2720-32.

6. Gong MN. Genetic epidemiology of acute respiratory distress syndrome: implications for future prevention and treatment. Clin Chest Med. 2006;27(4):705-24; abstract.

7. Rubenfeld GD, Caldwell E, Peabody E, Weaver J, Martin DP, Neff M, Stern EJ, Hudson LD. Incidence and outcomes of acute lung injury. N Engl J Med. 2005;353(16):1685-93.

8. Mikkelsen ME, Shah CV, Meyer NJ, et al. The epidemiology of acute respiratory distress syndrome in patients presenting to the emergency department with severe sepsis. Shock. 2013;40(5):375-81.

9. The Australia and New Zealand Extracorporeal Membrane Oxygenation (ANZ ECMO) Influenza Investigators*. Extracorporeal membrane oxygenation for 2009 influenza A (H1N1) acute respiratory distress syndrome. JAMA. 2009;302(17):1888-95. https://doi.org/10.1001/ jama.2009.1535.

10. Lee KY. Pneumonia, acute respiratory distress syndrome, and early immune-modulator therapy. Int J Mol Sci. 2017;18(2):388. https://doi.org/10.3390/ijms18020388. Published 2017 Feb 11.

11. Tomashefski JF Jr. Pulmonary pathology of the adult respiratory distress syndrome. Clin Chest Med. 1990;11(4):593-619.

12. Bernard GR. Acute respiratory distress syndrome: a historical perspective. Am J Respir Crit Care Med. 2005;172(7):798-806. https://doi.org/10.1164/rccm.200504-663OE.

13. Hill NS, Garpestad E, Schumaker G, Spoletini G. Noninvasive ventilation for acute hypoxemic respiratory failure/ARDS—is there a role? Turk J Anaesthesiol Reanim. 2017;45:332-4.

14. Writing Group for the Alveolar Recruitment for Acute Respiratory Distress Syndrome Trial (ART) Investigators, Cavalcanti AB, Suzumura ÉA, et al. Effect of lung recruitment and titrated positive end-expiratory pressure (PEEP) vs low PEEP on mortality in patients with acute respiratory distress syndrome: a randomized clinical trial. JAMA. 2017;318(14):133545. https://doi.org/10.1001/jama.2017.14171.

15. Scala R, Heunks L. Highlights in acute respiratory failure. Eur Respir Rev. 2018;27(147):180008. https://doi.org/10.1183/16000617.0008-2018.

16. Scala R. Challenges on non-invasive ventilation to treat acute respiratory failure in the elderly. BMC Pulm Med. 2016;16(1):150. https://doi.org/10.1186/s12890-016-0310-5. Published 2016 Nov 15.

17. Roca O, Riera J, Torres F, Masclans JR. High-flow oxygen therapy in acute respiratory failure. Respir Care. 2010;55(4):408-13. 